\title{
Effect of Elevated Left Ventricular End Diastolic Pressure on Instantaneous Wave-Free Ratio and Fractional Flow Reserve Discordance
}

\author{
Hassan Tahira, b, James Livesay ${ }^{\mathrm{a}}$, Benjamin Fogelson ${ }^{\mathrm{a}}$, Raj Baljepally ${ }^{\mathrm{a}}$
}

\begin{abstract}
Background: Instantaneous wave-free ratio (iFR)-guided physiological assessment has been shown to be non-inferior to fractional flow reserve (FFR)-guided assessment for deciding best treatment strategy for angiographically intermediate stenosis. The diagnostic accuracy of iFR compared to FFR reported in various studies is around $80 \%$. Many factors can lead to iFR/FFR discordance, though underlying physiological mechanism of discordance and its associated factors have not been fully evaluated. The effect of left ventricle end diastolic pressure (LVEDP) on $\mathrm{iFR} / \mathrm{FFR}$ discordance is unknown and needs further evaluation.
\end{abstract}

Methods: We performed a single center, non-randomized, both retrospective and prospective study. A total of 65 patients with intermediate coronary stenosis undergoing physiological assessment were included in the study. Patients were assigned to two groups (normal LVEDP and high LVEDP group) based on LVEDP cutoff of $15 \mathrm{~mm}$ Hg. iFR and FFR were measured for each patient and iFR/FFR results were compared between the two groups.

Results: A significantly large number of patients in elevated LVEDP group had iFR/FFR discordance compared to normal LVEDP group $(42.8 \%$ vs. $6.7 \%, \mathrm{P}=0.001)$. More patients with acute coronary syndrome (ACS) had discordance compared to stale coronary artery disease $(\mathrm{CAD})$ patients $(53 \%$ vs. $15 \%, \mathrm{P}=0.003)$.

Conclusions: Elevated LVEDP can affect iFR and FFR measurements and can lead to discordance. Further studies are required to determine effect of elevated LVEDP on iFR/FFR discordance and whether such discordance is clinically relevant. "Normal range" iFR results should be cautiously interpreted in patients with elevated LVEDP, especially those with ACS.

Keywords: Physiological assessment; iFR; FFR; iFR/FFR discord-

Manuscript submitted January 26, 2021, accepted February 9, 2021

Published online February 23, 2021

aDepartment of Cardiology, Heart Lung Vascular Institute, University of Tennessee Medical Center, Knoxville, TN, USA

${ }^{b}$ Corresponding Author: Hassan Tahir, University of Tennessee Medical Center in Knoxville, 1924 Alcoa Hwy, Knoxville, TN 37920, USA.

Email: doctorhassantahir@gmail.com

doi: https://doi.org/10.14740/cr1230 ance; Elevated LVEDP

\section{Introduction}

The benefit from coronary revascularization in patients with stable ischemic heart disease (SIHD) and angiographically intermediate coronary artery stenosis depends on the functional significance of the lesion [1, 2]. Hemodynamic assessment with instantaneous wave-free ratio (iFR) and fractional flow reserve (FFR) can access functional severity of coronary stenosis in such patients and overcome the uncertainty associated with angiographic estimation. Landmark randomized control trials have shown that physiology-guided percutaneous coronary intervention (PCI) in SIHD reduces unnecessary stenting and improves clinical outcomes [1,2]. Validation studies have shown good correlation between FFR and noninvasive stress tests [3-7]. Functional assessment using FFR is considered for physiological assessment of coronary lesions in stable ischemic heart disease [1, $2,8,9]$, however, adoption of FFR in clinical practice remains limited due to multiple factors [10-12]. In order to improve utilization of functional testing, resting non-hyperemic pressure ratio indices such as iFR have been developed which do not require vasodilators [13]. By reducing the procedure time and avoiding side effects of vasodilators, the iFR procedure is appealing and therefore more acceptable [12]. Recent trials have shown that the overall diagnostic accuracy of iFR is similar to FFR [14-16]. Several studies have evaluated various factors which can lead to iFR and FFR discordance. The underlying mechanism leading to such discordance is still unknown though various hypotheses have been proposed. Elevated left ventricle end diastolic pressure (LVEDP) affects microvascular circulation and therefore iFR and FFR measurements, though no study has evaluated the effects of elevated LVEDP on their discordance. The aim of our study was to assess whether elevated LVEDP is associated with increased discordance between iFR and FFR.

\section{Materials and Methods}

\section{Study design}

Our study is a single center, non-randomized both retrospec- 
tive and prospective study performed at the University of Tennessee Medical Center, Knoxville, TN, USA. The study was approved by institutional research board (IRB). This study was conducted in compliance with the ethical standards of the responsible institution on human subjects as well as with the Helsinki Declaration.

\section{Study population}

The study included patients with angiographically intermediate stenosis (50-70\%) undergoing iFR and FFR for physiological assessment. The patients were divided based on LVEDP into normal LVEDP and elevated LVEDP groups. The iFR and FFR were measured in each study patient and results were compared between the two groups. All patients had baseline $\mathrm{iFR} \geq 0.90$. Patients with $\mathrm{iFR} \leq 0.89$ were not included in the study as they underwent PCI without any further physiological testing. In patients with stable angina, any coronary vessel could be assessed; however, only nonculprit coronary vessels underwent physiological assessment in patients with acute coronary syndrome (ACS). Patients with end stage renal disease on hemodialysis, severe valvular heart disease, shock (any type), heart failure with the New York Heart Association (NYHA) class $\geq$ III, significant arrhythmias or artifacts affecting pressure waveform analysis, contraindication to intravenous (IV) adenosine, intubated patients and coronary artery bypass graft (CABG) patients requiring graft physiological assessment were excluded from the study.

\section{Procedural details}

Diagnostic coronary angiogram was performed via radial or femoral artery according to standard technique. Coronary arteries with intermediate stenosis on angiographic visual assessment underwent physiological assessment. All patients consented for the procedure. The angiographic images were reviewed by the primary proceduralist and degree of angiographic stenosis was estimated and documented. Functional assessment was performed according to standard procedural protocol. The iFR/FFR was measured using 0.014-inch pressure wire (Philips Volcano). Intracoronary nitroglycerine (200 - $300 \mu \mathrm{g})$ and IV heparin (70 - $100 \mathrm{IU} / \mathrm{kg}$ ) were given before the start of physiological assessment. The pressure wire was externally calibrated to zero and advanced through $6 \mathrm{~F}$ guide catheter to the ostium of left main where it was normalized to aortic pressure. The pressure wire was then positioned distal to the stenosis and iFR measurements were recorded for 30 $\mathrm{s}$. The guide catheter was flushed with heparinized saline before measuring iFR. The iFR was calculated as ratio of mean distal coronary pressure to mean aortic pressure during wavefree period (WFP) of diastole. We proceeded with FFR if iFR was $\geq 0.90$ which indicates hemodynamically non-significant stenosis. IV adenosine was given at $140 \mu \mathrm{g} / \mathrm{kg} / \mathrm{min}$ for a total of 2 min and FFR was measured. FFR was calculated as ratio of mean distal coronary pressure to mean aortic pressure at maximum hyperemia. At the conclusion of procedure, the pressure sensor was pulled back to the tip of guide catheter to confirm proper calibration and no drift. If a drift of \pm 0.02 was noted on pull back, the whole procedure was repeated again after adequate normalization. The pressure tracings were reviewed for artifacts or any arrhythmia affecting its reading. A threshold of 0.89 for iFR and 0.80 for FFR was used to indicate hemodynamic significance. These cutoffs were chosen based on landmark iFR and FFR trials. Patients with baseline iFR $\leq 0.89$ underwent revascularization and did not undergo FFR assessment. LVEDP was measured by crossing aortic valve with $5 \mathrm{~F}$ pigtail catheter and measuring LVEDP at end diastole which correlated with nadir of "a" wave on pressure tracing or onset of $\mathrm{R}$ wave on simultaneous electrocardiogram (EKG) tracing. LVEDP was measured at end expiration by averaging three consecutive beats.

\section{Data gathering and statistical analysis}

The demographics, clinical history, angiographic details and functional assessment data were collected and analyzed for each patient. Shapiro-Wilk normality test was used to determine normal distribution of variables in our study population. Continuous variables were expressed as means \pm standard deviation, and the difference between group means were analyzed with unpaired $t$-test. Categorical variables were expressed as proportions and percentages and difference between group proportions were analyzed using Fisher's exact test. A two-tailed $\mathrm{P}$ value of $<0.05$ was considered statistically significant. Statistical analysis was performed using GraphPad Prism, Version 9.

\section{Results}

A total of 65 patients with intermediate coronary lesions were included in the study. Patients were divided into two groups based on LVEDP. Patients with LVEDP $\leq 15 \mathrm{~mm} \mathrm{Hg}$ were assigned to normal LVEDP group $(n=30)$, and patients with LVEDP $>15 \mathrm{~mm} \mathrm{Hg}$ were assigned to elevated LVEDP group $(n=35)$.

\section{Baseline characteristics}

The baseline characteristics of patients are described in Table 1 . The mean age was $66.9 \pm 9.4$ and $28 \%$ were females. The two groups were similar with regards to demographics and risk factors; however more patients in elevated LVEDP group had diabetes mellitus $(17 \%$ vs. $40 \%, \mathrm{P}=0.06)$ and diastolic dysfunction on echocardiogram ( $6 \%$ vs. $34 \%, \mathrm{P}=$ $0.01)$. All the patients underwent $\mathrm{iFR} / \mathrm{FFR}$ in one coronary vessel. Forty-nine patients $(75 \%)$ had stable angina and 16 patients $(25 \%)$ had ACS as clinical presentation. A small fraction of patients had chronic kidney disease (CKD) stage 5 $(6 \%)$, previous CABG (7\%) and chronic systolic heart failure $(18 \%)$. The most common coronary artery interrogated with iFR and FFR was left anterior descending artery (LAD, 75\%) 
Table 1. Clinical, Angiographic and Hemodynamic Characteristics of Patients

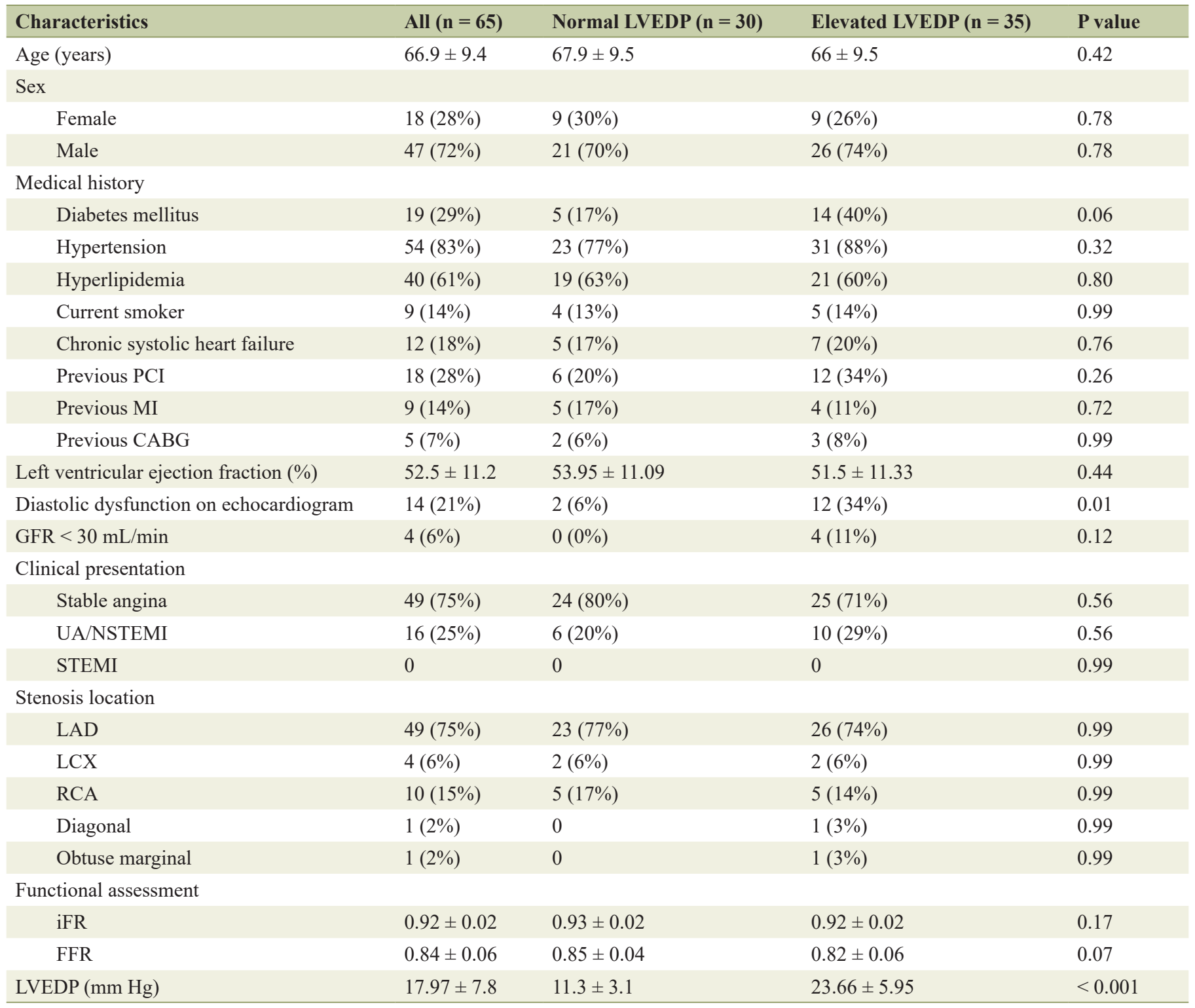

Variables are expressed as number (\%) or mean \pm standard deviation. $\mathrm{P}<0.05$ indicates difference between the groups is statistically significant. PCI: percutaneous coronary intervention; MI: myocardial infarction; CABG: coronary artery bypass graft; UA: unstable angina; NSTEMI: non-ST elevation myocardial infarction; STEMI: ST elevation myocardial infarction; LAD: left anterior descending artery; LCX: left circumflex artery; RCA: right coronary artery; iFR: instantaneous wave-free ratio; FFR: fractional flow reserve; LVEDP: left ventricular end diastolic pressure.

followed by right coronary artery $(15 \%)$ and left circumflex artery $(6 \%)$.

\section{Relationship between LVEDP and iFR/FFR}

The mean LVEDP of patient population was $17.97 \pm 7.8 \mathrm{~mm}$ $\mathrm{Hg}$, and mean iFR and FFR were $0.92 \pm 0.02$ and $0.84 \pm 0.06$ respectively. A total of 17 patients $(26 \%)$ had discordance between iFR and FFR in the study population. Fifteen patients $(42.8 \%)$ in elevated LVEDP group had iFR/FFR discordance compared to only two patients $(6.7 \%)$ in normal LVEDP group
$(\mathrm{P}=0.001)$ (Fig. 1). The mean LVEDP in patients with discordance was $24.5 \mathrm{~mm} \mathrm{Hg}$ and mean LVEDP in patients with concordance was $15.6 \mathrm{~mm} \mathrm{Hg}$ (Fig. 2). The majority (53\%) of patients with discordance had LVEDP $>25 \mathrm{~mm} \mathrm{Hg}$ as shown in frequency distribution graphical presentation (Fig. 3). Significantly increased discordance $(53 \%)$ was noted in patients presenting with ACS compared to only $15 \%$ in patients presenting with stable coronary artery disease (CAD) (Fig. 4). Fifteen out of 17 discordant patients $(88 \%)$ had iFR between 0.90 and 0.92 (Fig. 5). A scattered plot graphical presentation of iFR and FFR distribution including discordance in each group is presented in Figure 6. 


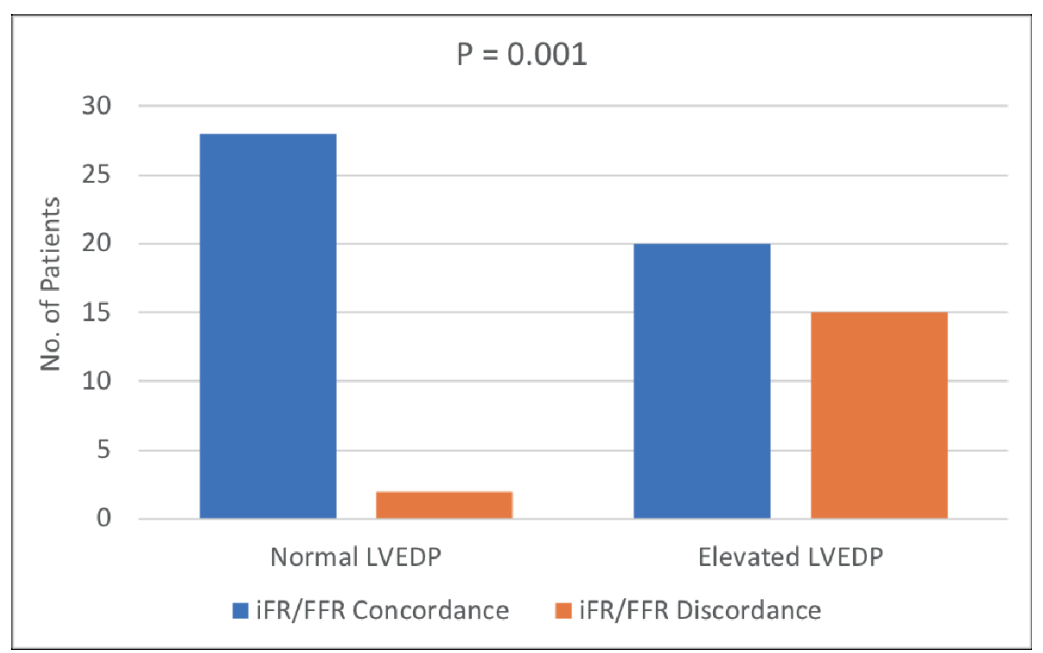

Figure 1. Comparison of iFR/FFR concordance and discordance between normal and elevated LVEDP groups. Significant number of patients in elevated LVEDP group had iFR/FFR discordance. $\mathrm{P}<0.05$ indicates statistical significance. iFR: instantaneous wave-free ratio; FFR: fractional flow reserve; LVEDP: left ventricular end diastolic pressure.

\section{Discussion}

Our study assessed the iFR/FFR discordance in patients with normal LVEDP compared to those with elevated LVEDP. A

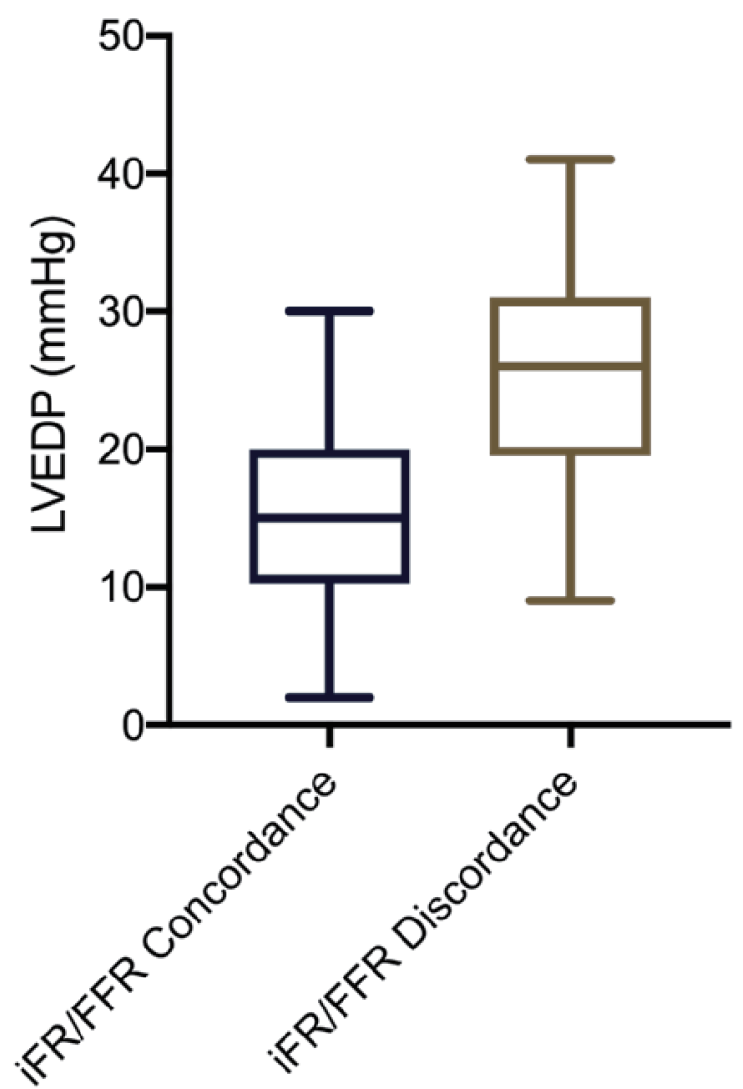

Figure 2. Mean LVEDP with range in iFR/FFR concordance and discordance patients. iFR: instantaneous wave-free ratio; FFR: fractional flow reserve; LVEDP: left ventricular end diastolic pressure. cutoff of $15 \mathrm{~mm} \mathrm{Hg}$ was chosen in our study to differentiate normal and elevated LVEDP. Though different sources quote varied normal LVEDP values, various invasive and noninvasive hemodynamic studies indicate that LVEDP $<15 \mathrm{~mm} \mathrm{Hg}$ is associated with normal LV filling pressures [17-21]. FFR-guided PCI has been shown to have better clinical outcomes compared to angiographically guided PCI in stable CAD patients $[1,2$, $22,23]$. Deferring hemodynamically non-significant lesions based on FFR in such patients also leads to better outcomes [24-26]. The 2011 American College of Cardiology Foundation (ACCF)/American Heart Association (AHA)/Society of Cardiovascular Angiography and Interventions (SCAI) guidelines gave class IIa recommendation for use of FFR evaluation of intermediate stenosis in stable CAD patients [27]. Expert consensus statement on the use of fractional flow reserve from SCAI recommends FFR use in SIHD patients with intermediate coronary stenosis when noninvasive imaging is unavailable, nondiagnostic, or discordant [28]. Despite bulk of evidence, use of FFR in clinical practice is low, attributed mainly to cost as well as side effects of the drug, increased length of procedure and possibly lack of reimbursement [10, 29-31]. It is estimated that only $6.1 \%$ of patients undergo FFR for evaluation of intermediate coronary stenosis [10]. This led to a shift in focus to non-hyperemic pressure indices such as iFR, which do not require vasodilators, the practical use of which has been compared to FFR and validated in various studies. Two large randomized control trials, DEFINE-FLAIR and iFR-SWEDEHEART demonstrated that iFR was non-inferior to FFR in terms of 1-year clinical outcomes [29, 32]. The many advantages of iFR including its ease of use, cost effectiveness and lack of medication requirement led to its recent enhanced use. Increased use of iFR is based on the assumption that it is similar to FFR in the physiological assessment of borderline coronary lesions. ADVISE II and RESOLVE trials were designed to determine the diagnostic accuracy of iFR and FFR $[14,33]$. Interestingly, the diagnostic accuracy of iFR was found to be approximately $80 \%$, indicating a discordance of around $20 \%$ 


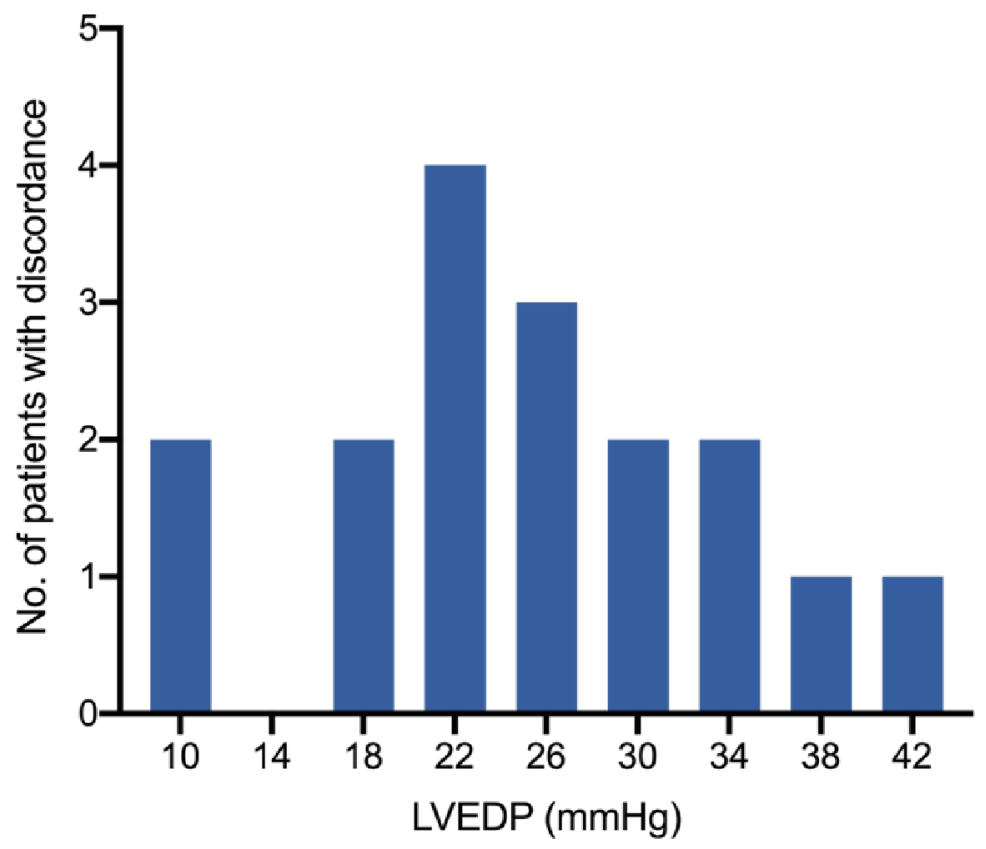

Figure 3. Frequency distribution of discordant patients according to LVEDP indicating that more than half of patients with iFR/ FFR discordance had LVEDP > 25 mm Hg. iFR: instantaneous wave-free ratio; FFR: fractional flow reserve; LVEDP: left ventricular end diastolic pressure.

between iFR and FFR [14, 33]. iFR and FFR have different physiological mechanisms; one is performed at rest and other at hyperemia, respectively, which might explain such discordance. However, the underlying mechanism of discordance and its associated factors have not been fully evaluated. Similarly, the best treatment strategy of such discordant lesions has not been fully investigated either, though most interventional cardiologists would proceed with revascularization if FFR $\leq 0.80$ as there is more data with FFR and it may possibly be less impacted by factors such as fluctuation in LVEDP. There is one recent study which assessed the clinical outcome of iFR/FFR discordant patients and found no increase in major adverse cardiovascular (CV) events in such patients [34].

Our study indicates that elevated LVEDP is an important factor which can influence non-hyperemic pressure measurements and affect validity of functional testing. Fewer studies have sought to identify the specific factors leading to discordance between iFR and FFR. One clinical study performed by Derimay et al indicated that stenosis location, stenosis degree, heart rate, age and use of beta blockers can influence concordance with FFR and should be taken into account when interpreting iFR [35]. Satomi et al determined that lower heart

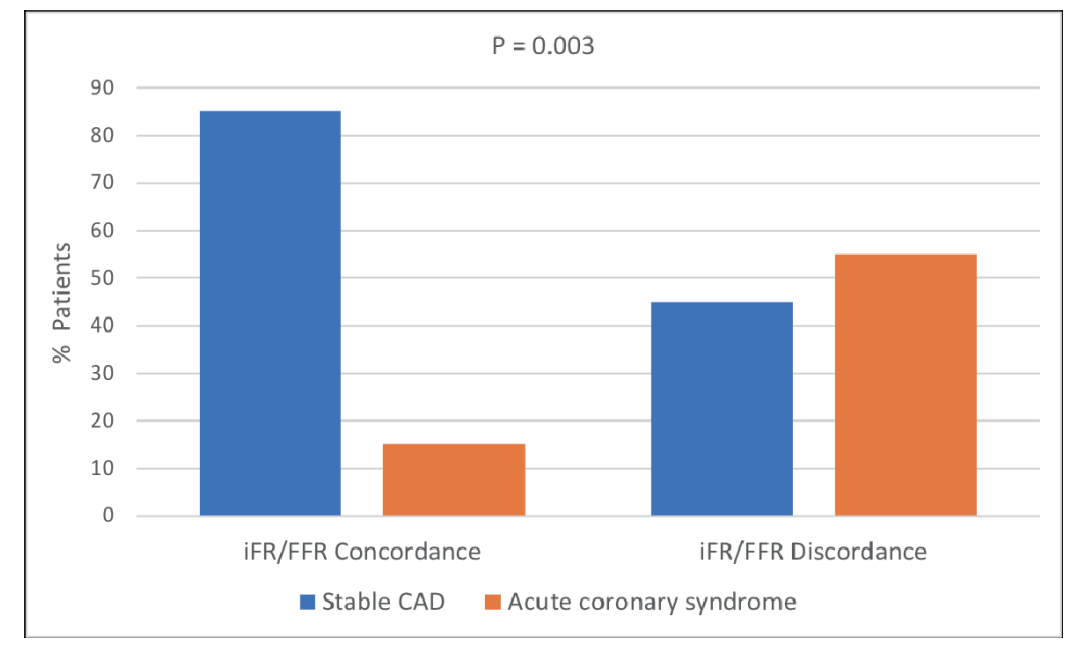

Figure 4. Comparison of iFR/FFR concordance and discordance according to stable CAD and acute coronary syndrome. Significantly more patients with acute coronary syndrome had iFR/FFR discordance. $\mathrm{P}<0.05$ indicates statistical significance. iFR: instantaneous wave-free ratio; FFR: fractional flow reserve; CAD: coronary artery disease. 


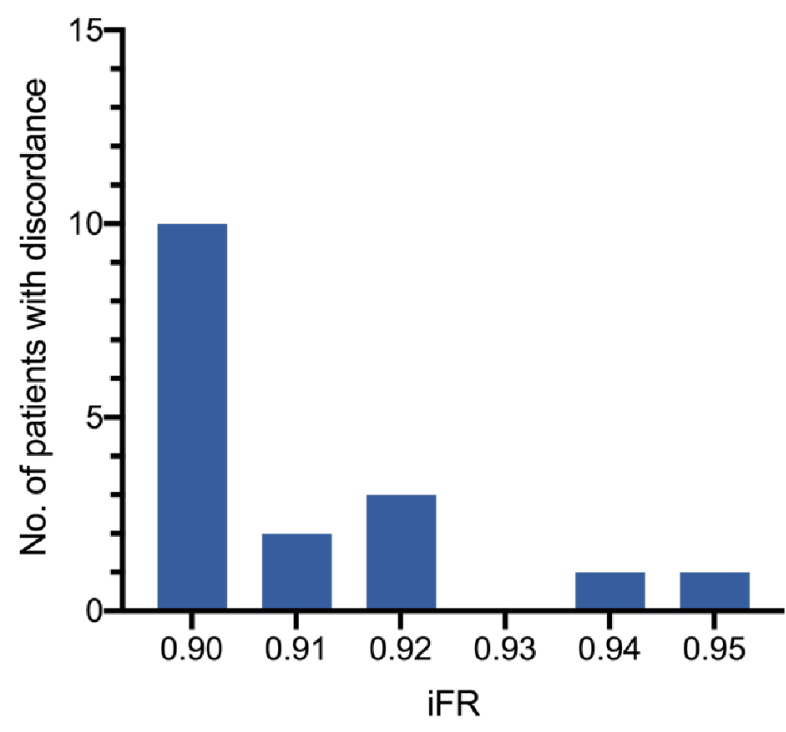

Figure 5. Frequency distribution of discordant patients according to iFR. Most of the patients with iFR/FFR discordance had iFR between 0.90 and 0.92 . iFR: instantaneous wave-free ratio; FFR: fractional flow reserve.

rate, lower pressure rate product, lower cardiac index and non-hemodialysis patients were predictors of negative discordance in patients undergoing iFR and FFR [36]. A recently published study evaluated predictors of discordance between resting flow reserve (RFR) and FFR. The study found that left main stenosis, LAD stenosis, hemodialysis, peripheral artery disease, absence of diabetes mellitus and anemia can be inde- pendent predictors of physiologic discordance between RFR and FFR [37]. Although the underlying mechanism of iFR/ FFR discordance is unclear, it could be related to differences in hyperemic coronary blood flow [38] and individual variation in microcirculatory response. In one study, discordance group (low FFR despite high iFR) showed significant difference in microvascular resistance, trans stenosis resistance, absolute myocardial blood flow and coronary flow reserve compared to concordant abnormal group [39]. Ge et al concluded that an increase in coronary microvascular resistance can lead to an increase in both iFR and FFR indices, however the magnitude of FFR increase is greater than that of iFR [40]. A similar study demonstrated that patients with iFR and FFR discordance had differences in their coronary microvascular resistance during resting and hyperemic states [41]. There is paucity of data regarding the effects of LVEDP on iFR/FFR measurements. Landmark iFR and FFR clinical trials did not evaluate LVEDP in their respective patient population. To our knowledge, no prior studies have evaluated the effect of LVEDP on discordance of physiological indices. There are few studies which assessed the LVEDP effect on iFR or FFR measurements but not their discordance [42]. One small study evaluated the effect of LVEDP on FFR which showed positive correlation with FFR [42]. The association was greater in FFR $<0.80$ and with low blood pressure [42]. Another study concluded that E/E' on echocardiogram can affect iFR [43]. The effect of LVEDP on myocardial perfusion has been evaluated in previous studies. Elevated LVEDP can impede myocardial perfusion and can cause microvascular ischemia [44]. We hypothesize that variation in coronary microcirculation due to elevated LVEDP may be the underlying mechanism of discordance.

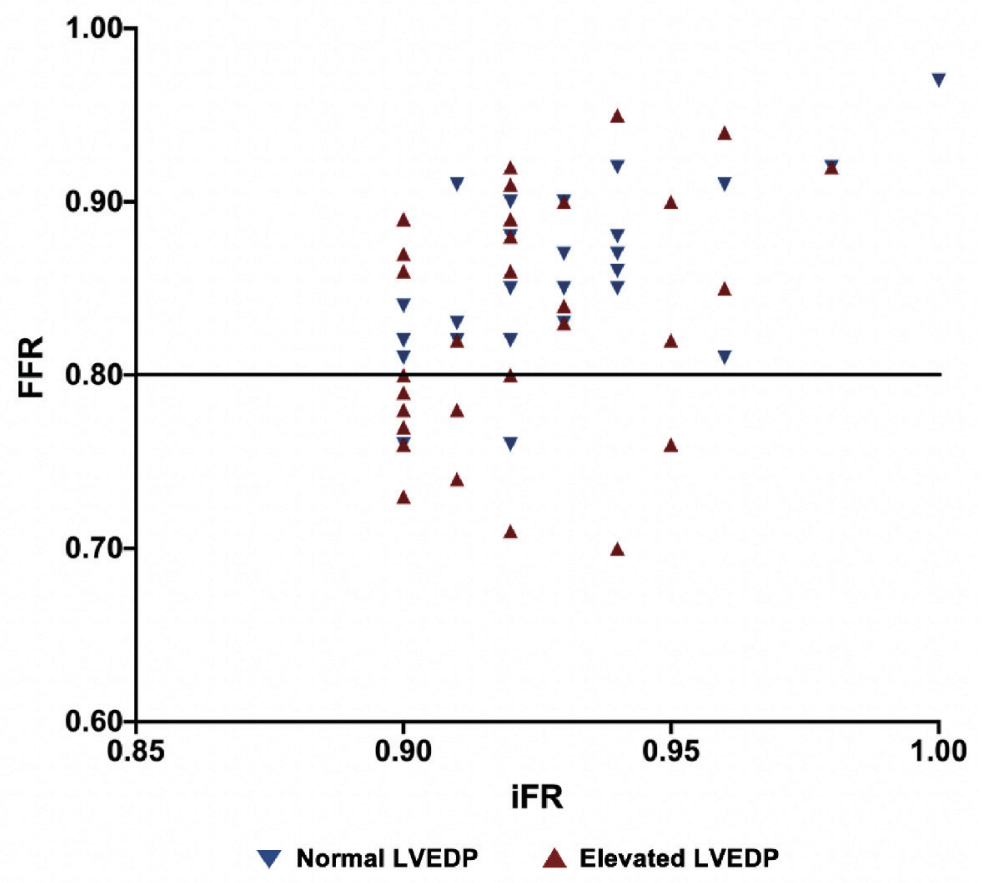

Figure 6. Scatter plot graph showing iFR and FFR distribution in patient population. Data below the FFR cutoff of 0.80 indicate discordance. iFR: instantaneous wave-free ratio; FFR: fractional flow reserve; LVEDP: left ventricular end diastolic pressure. 
Our study included disproportionate number of patients with ACS. We performed physiological assessment of nonculprit coronary lesions in such patients as recent trials have supported the reliability of iFR and FFR in assessment of non-infarct related artery in ACS patients. Most ACS patients in our study population had elevated LVEDP and large proportion of ACS patients had discordance which might be due to elevated LVEDP in such patients. As mentioned earlier, landmark clinical trials accessing FFR and iFR did not assess LVEDP while including mostly stable CAD patients which are more likely to have normal LVEDP compared to ACS patients. DANAMI3-PRIMALTI and COMPARE-ACUTE trials evaluated FFRguided angioplasty in ACS without focusing on LVEDP [45, 46]. Similarly, trials on iFR/FFR discordance did not factor effects of LVEDP. Our study indicates that elevated LVEDP might be an important determinant to discordance. With emerging use of iFR, most physicians rely solely on iFR for identifying hemodynamically significant stenosis, a strategy fraught with limitations in patients with elevated LVEDP, as noted in our study. Elevated LVEDP as reported in our study can lead to inherent variability of iFR and FFR measurement, which can affect diagnostic accuracy. Hybrid iFR/FFR study may be preferable strategy in such patients. Hybrid strategy in our study patients with elevated LVEDP was able to successfully identify increased number of patients having hemodynamically significant stenosis based on FFR despite a normal iFR. Since a large number of patients in clinical practice, specifically those with ACS and systolic or diastolic heart failure, have significantly elevated LVEDP and since functional assessment of coronary lesions in such patients may be affected by elevated LVEDP, further evaluation with FFR should be performed routinely, to improve diagnostic accuracy of functional assessment in all patients with borderline iFR (0.90 0.93 ) and elevated LVEDP.

\section{Limitations}

The main limitations of our study are small sample size and non-randomization. In addition, our study did not assess positive iFR with negative FFR discordance, which may also be affected by elevated LVEDP given that all patients with hemodynamically significant iFR $(\leq 0.89)$ underwent PCI without proceeding to FFR and were not included in the study. Also, our study included significant proportion of ACS patients. Even though there is emerging scientific data regarding use of physiological assessment in ACS patients, particularly in the evaluation of nonculprit vessel, there is no large randomized controlled trial evaluating the validity of $\mathrm{iFR} / \mathrm{FFR}$ in ACS patients.

\section{Conclusions}

In conclusion, our study found that elevated LVEDP is an important factor contributing significantly to iFR/FFR discordance. Given the high prevalence of elevated LVEDP in clinical practice, further research is warranted to evaluate this impor- tant association and its clinical implications.

\section{Acknowledgments}

None to declare.

\section{Financial Disclosure}

None to declare.

\section{Conflict of Interest}

The authors report no conflict of interest regarding the content herein.

\section{Informed Consent}

Informed consents were obtained.

\section{Author Contributions}

Hassan Tahir and Raj Baljepally conceived and designed the study. Hassan Tahir, James Livesay and Benjamin Fogelson performed data gathering. Hassan Tahir and Raj Baljepally performed the statistical analysis and wrote the manuscript. All authors performed the critical revision of article and approved the final version of manuscript.

\section{Data Availability}

The data supporting the findings of this study are available from the corresponding author upon reasonable request.

\section{Abbreviations}

iFR: instantaneous wave-free ratio; FFR: fractional flow reserve; LVEDP: left ventricle end diastolic pressure; WFP: wave-free period; PCI: percutaneous coronary intervention; ACS: acute coronary syndrome; CAD: coronary artery disease; SIHD: stable ischemic heart disease

\section{References}

1. Tonino PA, De Bruyne B, Pijls NH, Siebert U, Ikeno F, van' t Veer M, Klauss V, et al. Fractional flow reserve versus angiography for guiding percutaneous coronary intervention. N Engl J Med. 2009;360(3):213-224.

2. De Bruyne B, Pijls NH, Kalesan B, Barbato E, Tonino PA, Piroth Z, Jagic N, et al. Fractional flow reserve-guided PCI versus medical therapy in stable coronary disease. 
N Engl J Med. 2012;367(11):991-1001.

3. Yanagisawa H, Chikamori T, Tanaka N, Hatano T, Morishima T, Hida S, Iino H, et al. Correlation between thallium-201 myocardial perfusion defects and the functional severity of coronary artery stenosis as assessed by pressure-derived myocardial fractional flow reserve. Circ J. 2002;66(12):1105-1109.

4. Christou MA, Siontis GC, Katritsis DG, Ioannidis JP. Meta-analysis of fractional flow reserve versus quantitative coronary angiography and noninvasive imaging for evaluation of myocardial ischemia. Am J Cardiol. 2007;99(4):450-456.

5. Kruger S, Koch KC, Kaumanns I, Merx MW, Schafer WM, Buell U, Hanrath P, et al. Use of fractional flow reserve versus stress perfusion scintigraphy in stent restenosis. Eur J Intern Med. 2005;16(6):429-431.

6. Erhard I, Rieber J, Jung P, Hacker M, Schiele T, Stempfle HU, Konig A, et al. The validation of fractional flow reserve in patients with coronary multivessel disease: a comparison with SPECT and contrast-enhanced dobutamine stress echocardiography. Z Kardiol. 2005;94(5):321-327.

7. De Bruyne B, Baudhuin T, Melin JA, Pijls NH, Sys SU, Bol A, Paulus WJ, et al. Coronary flow reserve calculated from pressure measurements in humans. Validation with positron emission tomography. Circulation. 1994;89(3):1013-1022.

8. Pijls NH, Sels JW. Functional measurement of coronary stenosis. J Am Coll Cardiol. 2012;59(12):1045-1057.

9. Pijls NH, De Bruyne B, Peels K, Van Der Voort PH, Bonnier HJ, Bartunek JKJJ, Koolen JJ. Measurement of fractional flow reserve to assess the functional severity of coronary-artery stenoses. N Engl J Med. 1996;334(26):1703-1708.

10. Dattilo PB, Prasad A, Honeycutt E, Wang TY, Messenger JC. Contemporary patterns of fractional flow reserve and intravascular ultrasound use among patients undergoing percutaneous coronary intervention in the United States: insights from the National Cardiovascular Data Registry. J Am Coll Cardiol. 2012;60(22):2337-2339.

11. Zhang D, Lv S, Song X, Yuan F, Xu F, Zhang M, Yan S, et al. Fractional flow reserve versus angiography for guiding percutaneous coronary intervention: a meta-analysis. Heart. 2015;101(6):455-462.

12. van de Hoef TP, Lee JM, Echavarria-Pinto M, Koo BK, Matsuo H, Patel MR, Davies JE, et al. Non-hyperaemic coronary pressure measurements to guide coronary interventions. Nat Rev Cardiol. 2020;17(10):629-640.

13. Sen S, Escaned J, Malik IS, Mikhail GW, Foale RA, Mila $\mathrm{R}$, Tarkin J, et al. Development and validation of a new adenosine-independent index of stenosis severity from coronary wave-intensity analysis: results of the ADVISE (ADenosine Vasodilator Independent Stenosis Evaluation) study. J Am Coll Cardiol. 2012;59(15):1392-1402.

14. Jeremias A, Maehara A, Genereux P, Asrress KN, Berry C, De Bruyne B, Davies JE, et al. Multicenter core laboratory comparison of the instantaneous wave-free ratio and resting $\mathrm{Pd} / \mathrm{Pa}$ with fractional flow reserve: the RESOLVE study. J Am Coll Cardiol. 2014;63(13):1253-1261.

15. Shiode N, Okimoto T, Tamekiyo H, Kawase T, Yamane
K, Kagawa Y, Fujii Y, et al. A Comparison between the instantaneous wave-free ratio and resting distal coronary artery pressure/aortic pressure and the fractional flow reserve: the diagnostic accuracy can be improved by the use of both indices. Intern Med. 2017;56(7):749-753.

16. Maini R, Moscona J, Katigbak P, Fernandez C, Sidhu G, Saleh Q, Irimpen A, et al. Instantaneous wave-free ratio as an alternative to fractional flow reserve in assessment of moderate coronary stenoses: A meta-analysis of diagnostic accuracy studies. Cardiovasc Revasc Med. 2018;19(5 Pt B):613-620.

17. Mulvagh S, Quinones MA, Kleiman NS, Cheirif J, Zoghbi WA. Estimation of left ventricular end-diastolic pressure from Doppler transmitral flow velocity in cardiac patients independent of systolic performance. J Am Coll Cardiol. 1992;20(1):112-119.

18. Zhang F, Liang Y, Chen X, Xu L, Zhou C, Fan T, Yan J. Echocardiographic evaluation of left ventricular end diastolic pressure in patients with diastolic heart failure: A comparative study with real-time catheterization. Medicine (Baltimore). 2020;99(49):e22683.

19. Zhou X, Lei M, Zhou D, Li G, Duan Z, Zhou S, Jin Y. Clinical factors affecting left ventricular end-diastolic pressure in patients with acute ST-segment elevation myocardial infarction. Ann Palliat Med. 2020;9(4):18341840.

20. Lancellotti P, Galderisi M, Edvardsen T, Donal E, Goliasch G, Cardim N, Magne J, et al. Echo-Doppler estimation of left ventricular filling pressure: results of the multicentre EACVI Euro-Filling study. Eur Heart J Cardiovasc Imaging. 2017;18(9):961-968.

21. Rosenkranz S, Gibbs JS, Wachter R, De Marco T, Vonk-Noordegraaf A, Vachiery JL. Left ventricular heart failure and pulmonary hypertension. Eur Heart J. 2016;37(12):942-954.

22. Li J, Elrashidi MY, Flammer AJ, Lennon RJ, Bell MR, Holmes DR, Bresnahan JF, et al. Long-term outcomes of fractional flow reserve-guided vs. angiography-guided percutaneous coronary intervention in contemporary practice. Eur Heart J. 2013;34(18):1375-1383.

23. Ahn JM, Park DW, Shin ES, Koo BK, Nam CW, Doh $\mathrm{JH}, \mathrm{Kim} \mathrm{JH}$, et al. Fractional Flow Reserve and Cardiac Events in Coronary Artery Disease: Data From a Prospective IRIS-FFR Registry (Interventional Cardiology Research Incooperation Society Fractional Flow Reserve). Circulation. 2017;135(23):2241-2251.

24. Zimmermann FM, Ferrara A, Johnson NP, van Nunen LX, Escaned J, Albertsson P, Erbel R, et al. Deferral vs. performance of percutaneous coronary intervention of functionally non-significant coronary stenosis: 15-year follow-up of the DEFER trial. Eur Heart J. 2015;36(45):3182-3188.

25. Muller O, Mangiacapra F, Ntalianis A, Verhamme KM, Trana C, Hamilos M, Bartunek J, et al. Long-term follow-up after fractional flow reserve-guided treatment strategy in patients with an isolated proximal left anterior descending coronary artery stenosis. JACC Cardiovasc Interv. 2011;4(11):1175-1182.

26. Van Belle E, Rioufol G, Pouillot C, Cuisset T, Bougrini $\mathrm{K}$, Teiger E, Champagne S, et al. Outcome impact of 
coronary revascularization strategy reclassification with fractional flow reserve at time of diagnostic angiography: insights from a large French multicenter fractional flow reserve registry. Circulation. 2014;129(2):173-185.

27. Levine GN, Bates ER, Blankenship JC, Bailey SR, Bittl JA, Cercek B, Chambers CE, et al. 2011 ACCF/AHA/ SCAI Guideline for Percutaneous Coronary Intervention: a report of the American College of Cardiology Foundation/American Heart Association Task Force on Practice Guidelines and the Society for Cardiovascular Angiography and Interventions. Circulation. 2011;124(23):e574651.

28. Lotfi A, Jeremias A, Fearon WF, Feldman MD, Mehran R, Messenger JC, Grines CL, et al. Expert consensus statement on the use of fractional flow reserve, intravascular ultrasound, and optical coherence tomography: a consensus statement of the Society of Cardiovascular Angiography and Interventions. Catheter Cardiovasc Interv. 2014;83(4):509-518.

29. Davies JE, Sen S, Dehbi HM, Al-Lamee R, Petraco R, Nijjer SS, Bhindi R, et al. Use of the Instantaneous Wave-free Ratio or Fractional Flow Reserve in PCI. N Engl J Med. 2017;376(19):1824-1834.

30. Kern MJ, Seto AH. On the search for an "easy" FFR: Submaximal hyperemia and NTG-induced translesional pressure drop ( $\mathrm{Pd} / \mathrm{Pa}-\mathrm{NTG})$. Catheter Cardiovasc Interv. 2016;87(2):270-272.

31. Mallet ML. Proarrhythmic effects of adenosine: a review of the literature. Emerg Med J. 2004;21(4):408-410.

32. Gotberg M, Christiansen EH, Gudmundsdottir IJ, Sandhall L, Danielewicz M, Jakobsen L, Olsson SE, et al. Instantaneous wave-free ratio versus fractional flow reserve to guide PCI. N Engl J Med. 2017;376(19):1813-1823.

33. Escaned J, Echavarria-Pinto M, Garcia-Garcia HM, van de Hoef TP, de Vries T, Kaul P, Raveendran G, et al. Prospective assessment of the diagnostic accuracy of instantaneous wave-free ratio to assess coronary stenosis relevance: results of ADVISE II international, multicenter study (ADenosine Vasodilator Independent Stenosis Evaluation II). JACC Cardiovasc Interv. 2015;8(6):824833.

34. Lee SH, Choi KH, Lee JM, Hwang D, Rhee TM, Park J, Kim HK, et al. Physiologic Characteristics and Clinical Outcomes of Patients With Discordance Between FFR and iFR. JACC Cardiovasc Interv. 2019;12(20):20182031.

35. Derimay F, Johnson NP, Zimmermann FM, Adjedj J, Witt N, Hennigan B, Koo BK, et al. Predictive factors of discordance between the instantaneous wave-free ratio and fractional flow reserve. Catheter Cardiovasc Interv. 2019;94(3):356-363.

36. Satomi N, Ishida I, Arashi H, et al. Abstract 16416: predictors of discordance between instantaneous wave- free ration and fractional flow reserve. Circulation. 2017;136:A16416.

37. Goto R, Takashima H, Ohashi H, et al. Independent predictors of discordance between the resting full-cycle ratio and fractional flow reserve [published online ahead of print, 2021 Jan 5]. Heart Vessels. 2021.

38. Cook CM, Jeremias A, Petraco R, Sen S, Nijjer S, ShunShin MJ, Ahmad Y, et al. Fractional flow reserve/instantaneous wave-free ratio discordance in angiographically intermediate coronary stenoses: an analysis using doppler-derived coronary flow measurements. JACC Cardiovasc Interv. 2017;10(24):2514-2524.

39. Lee JM, Hwang D, Park J, Tong Y, Koo BK. Physiologic mechanism of discordance between instantaneous wavefree ratio and fractional flow reserve: Insight from (13)Nammonium positron emission tomography. Int $\mathrm{J}$ Cardiol. 2017;243:91-94.

40. Ge X, Liu Y, Yin Z, Tu S, Fan Y, Vassilevski Y, Simakov S, et al. Comparison of instantaneous wave-free ratio (iFR) and fractional flow reserve (FFR) with respect to their sensitivities to cardiovascular factors: a computational model-based study. J Interv Cardiol. 2020;2020:4094121.

41. Lee JM, Shin ES, Nam CW, Doh JH, Hwang D, Park J, Kim KJ, et al. Discrepancy between fractional flow reserve and instantaneous wave-free ratio: Clinical and angiographic characteristics. Int J Cardiol. 2017;245:63-68.

42. Leonardi RA, Townsend JC, Patel CA, Wolf BJ, Todoran TM, Fernandes VL, Nielsen CD, et al. Left ventricular end-diastolic pressure affects measurement of fractional flow reserve. Cardiovasc Revasc Med. 2013;14(4):218222.

43. Arashi H, Yamaguchi J, Ri T, Otsuki H, Nakao M, Kamishima K, Jujo K, et al. The impact of tissue Doppler index E/e' ratio on instantaneous wave-free ratio. J Cardiol. 2018;71(3):237-243.

44. Van Herck PL, Carlier SG, Claeys MJ, Haine SE, Gorissen P, Miljoen H, Bosmans JM, et al. Coronary microvascular dysfunction after myocardial infarction: increased coronary zero flow pressure both in the infarcted and in the remote myocardium is mainly related to left ventricular filling pressure. Heart. 2007;93(10):1231-1237.

45. Engstrom T, Kelbaek H, Helqvist S, Hofsten DE, Klovgaard L, Holmvang L, Jorgensen E, et al. Complete revascularisation versus treatment of the culprit lesion only in patients with ST-segment elevation myocardial infarction and multivessel disease (DANAMI-3-PRIMULTI): an open-label, randomised controlled trial. Lancet. 2015;386(9994):665-671.

46. Smits PC, Abdel-Wahab M, Neumann FJ, Boxma-de Klerk BM, Lunde K, Schotborgh CE, Piroth Z, et al. Fractional flow reserve-guided multivessel angioplasty in myocardial infarction. N Engl J Med. 2017;376(13):12341244. 